\title{
Communication in the midst of Covid-19 pandemic
}

Benni Setiawan

Pawito Pawito

Sri Hastjarjo

Universitas Sebelas Maret, Indonesia

The Covid-19 pandemic does not end yet. The statistical number of its spread keeps escalating every day. Data, as of July 1, 2021, report 2,203,108 positive cases, 1,890,287 recovered people, and 58,995 deaths. This data may be smaller than the actual number. However, covid-19 is not merely a number. The number of sick and dead people due to this epidemic seems to be improper if it is only viewed from a mathematical calculation's perspective. They must be viewed as human beings who have the right to live and receive health insurance from the government.

Ironically, the efforts of the Indonesian government to date have not been able to decrease the spread and number of deaths due to Covid-19. Government policies are still changing frequently. Finally, the government imposed the Emergency Community Activity Restriction (PPKM) for the Java and Bali regions. This PPKM policy aims to replace micro-level PPKM, which did not significantly decline the spread of Covid-19.

This policy change in the communication frame is certainly confusing as the policy has a different name, but its essence remains the same. The changing name of the policy only confuses the communicant in the communication process. This confusion has led the policy to be more ineffective. People do not seem to have clear guidelines on what to do amid the Covid-19 pandemic.

This public confusion is certainly reasonable; for example, we can easily trace the digital footprint a year ago, where many state officials said that 
Covid-19 would not spread in Indonesia. Even in a joking tone, they said that Indonesian people were resistant to Covid-19 as they like to eat cat rice (rice with various sides wrapped in paper or banana leaves). There are many more uneducated speeches, which contrast to the powerless government in tackling the spread of Covid-19 in Indonesia.

This less responsive crisis communication has shaken nationalism. The government elite communication process should be adapted to the crisis; therefore, crisis communication is badly needed by the government elites. The government needs to speak that the nation's condition is critical. What they convey must be based on the facts, rather than joking or even underestimating the danger of Covid-19.

Communication performed by the government needs to be enhanced with reliable information dissemination, namely by controlling the rate of buzzer "chirps" on various social media. Government buzzers need to be well managed so that they do not just justify what the elite say. However, they need to oversee government policies ensuring the policy runs properly. Their job is not to omit critics. Criticism in the communication process of civilized society (Bonnum Commune) is necessary and important. Without considering other views, the government will be absolute, not to call it authoritarian.

The government does not need to worry about the critics. It is time for the government's political buzzer to report a valuable national and state life policy. It is not appropriate if those paid with public money respond to public criticism in an uncivilized manner.

The government is required to properly safeguard human life, namely by opening closed communication taps (Rayasam \& Mande, 2021). The government needs to facilitate the widest communication so that the Covid-19 pandemic ends soon. The government's openness to information and the chivalrous manner in responding to every criticism will speed up the recovery from COVID-19.

This open government communication can be realized by considering comparative data from several volunteers such as@kawalcovid19 and @ LaporCovid. This group of volunteers needs to be heard by the government as they provide valuable data to use. The data can be utilized to compare and enhance government's quick steps to take policies to save human lives.

Again, the process of communicating with this group of volunteers does 
not aim to attack or debate the collected data but as part of joint preparedness. This preparedness is a form of preventive communication where the government and the private sector can collaboratively work and support each other.

The creative process of communication to unravel the covid-19 is badly needed (Setiawan, 2020). One potential way to ensure appropriate risk communication is to utilize social media channels and establish a consistent and sustainable media presence (Abrams \& Greenhawt, 2020). Social media channels can be an effective communication channel to reduce the risk of Covid-19.

Effective communication, if neglected, will create gaps for vulnerable populations and generate more difficulties in fighting the COVID-19 pandemic (Reddy \& Gupta, 2020). The vulnerable population not only include the old people, but also those who are unable to access Covid-19 information properly.

Communicating disease and its prevention effort is an essential job, but educating people to access information properly is equally important. Hoaxes during a growing pandemic need to be tackled with an adequate literacy process (Setiawan, 2018; Stanley, Barr Peters, \& Seli, 2020). The mass media need to carry out humanitarian work to show the truth of the news. Moreover, the media must keep from drowning widely in the rapid information flow that leads to producing unreliable news (Setiawan, Pawito, Hastjarjo, 2020; Anwar, Malik, Raees, \& Anwar, 2020).

In addition, the communication problem during a pandemic deals with the lack of scientific communication. Science communication refers to the way an expert communicates scientific findings to an audience. Often, there is a gap among experts in conveying information or findings. This communication gap encourages that science communication is greatly required for unraveling the intricate threads of COVID-19.

Finally, the Covid-19 pandemic needs to be resolved with a variety of communication models. The more models and/or communication channels are, the faster information delivery and understanding of Covid-19 will be. Through this communication model, Covid-19 will no longer be a scourge for the government and society in general. We hope that this COVID-19 pandemic will end soon. 


\section{References}

Abrams, E. M., \& Greenhawt, M. (2020). Risk communication during COVID-19. The Journal of Allergy and Clinical Immunology: In Practice, 8(6), 1791-1794. https://doi.org/10.1016/j.jaip.2020.04.012

Anwar, A., Malik, M., Raees, V., \& Anwar, A. (2020). Role of mass media and public health communications in the COVID-19 pandemic. Cureus, 12(9). doi: 10.7759/cureus.10453

Rayasam, G. V. \& Mande, S. C. (2021). Communication in the times of COVID-19. Current Science, 120(10), 25 May. Retrieved from https:// www.currentscience.ac.in/Volumes/120/10/1556.pdf

Reddy, B. V., \& Gupta, A. (2020). Importance of effective communication during COVID-19 infodemic. Journal of Family Medicine and Primary Care, 9(8), 3793-3796. doi: 10.4103/jfmpc.jfmpc_719_20

Setiawan, B. (2018). Indonesia darurat hoaks?. Informasi, 48(2), v-vi. https://doi. org/10.21831/informasi.v48i2.23210

Setiawan, B. (2020). Global cooperation resolve the covid-19 pandemic. Informasi, 50(1), v-vi. https://doi.org/10.21831/informasi.v50i1.33519

Setiawan, B., Pawito, P., \& Hastjarjo, S. (2020). Hoax amidst the Covid-19 pandemic. DOI 10.4108/eai.4-8-2020.2302399.

Stanley, M. L., Barr, N., Peters, K., \& Seli, P. (2020). Analytic-thinking predicts hoax beliefs and helping behaviors in response to the COVID-19 pandemic. Thinking $\mathcal{E}$ Reasoning, 1-14. https://doi.org/10.1080/135467 83.2020 .1813806 